\title{
The Optimization Path of Artificial Intelligence Industry Development from the Perspective of Policy -Based on a Comparative Study Between China and the United States
}

\author{
Ruoyu $\mathrm{Luo}^{1}$, Lingli Liu ${ }^{2, *}$ \\ ${ }^{1}$ School of Public Affairs and Administration, University of Electronic Science and Technology of China, Chengdu, \\ Sichuan, 611731, China \\ ${ }^{2}$ School of Public Affairs and Administration, University of Electronic Science and Technology of China, Chengdu, \\ Sichuan, 611731, China \\ *Corresponding author. Email: 352563250@qq.com
}

\begin{abstract}
Artificial intelligence is setting off a development boom around the world, becoming the core driving force and leading force of a new round of scientific and technological revolution. How to promote the development of artificial intelligence through government leadership has become a consensus among governments of various countries. This article attempts to explore the development gap between different dimensions of the artificial intelligence industry in China and the United States from the perspective of country comparison between China and the United States. On this basis, sort out the US artificial intelligence industrial policy systematically, and draw on the relevant US industrial policies to discuss the optimization path of China's artificial intelligence industry development from the perspective of policy.
\end{abstract}

Keywords: policy perspective; artificial intelligence; comparative research; optimization path

\section{INTRODUCTION}

As the core driving force of a new round of industrial transformation, artificial intelligence will trigger major changes in the economic structure and become a new engine for economic development[1]. In order to seize the major opportunities for the development of artificial intelligence and promote the transformation and upgrading of the industrial structure, the Party Central Committee issued the "New Generation Artificial Intelligence Development Plan", "Three-year Action Plan to Promote the Development of the New Generation Artificial Intelligence Industry (2018-2020)", a series of strategic plans and policies such as "Internet + " Three-year Action on Artificial Intelligence "accelerate the development and innovation of China's artificial intelligence industry in order to seize the dominant position of a new round of scientific and technological revolution and improve China's international competitiveness.

The artificial intelligence industry refers to products and services that focus on key technologies of artificial intelligence such as deep learning, machine learning and robotics, and cover different fields of vision and hearing recognition, intelligent manufacturing, smart cities, unmanned driving, etc., Sales as one of the economic activities [2]. As one of the world's highest new frontier industries, artificial intelligence has both technical and social attributes. The disruptive breakthroughs achieved in the field of artificial intelligence are not just changes in this single field or this industry. Their impact will often drive the development of other industries and even affect the entire society, bringing about comprehensive changes in the entire society[3]. Enterprises and scientific research institutions are concerned about breakthroughs and innovations in artificial intelligence technology, and cannot make overall plans for the development of the artificial intelligence industry from a macro perspective. Most of the breakthrough scientific and technological progress from $\mathrm{R} \& \mathrm{D}$ to landing is inseparable from the support and guidance of the government as the main body of governance. As the most cutting-edge and breakthrough change in the world, artificial intelligence needs to play the role of the government as the main body of governance. In other words, the challenges encountered by the artificial intelligence industry in the development process are not enough to rely on the power of enterprises and scientific research institutions. It is necessary to rely on the government to make a series of public policy choices from the macro level of the top-level design to resolve the challenges facing the development of the artificial intelligence industry. A series of challenges. However, the current domestic academic research on the development of the artificial intelligence industry is mainly focused on the technical level. The main concern is the potential of the artificial intelligence industry and its integration with other industries. Few studies have 
systematically explored how the government can effectively pass the policy from a policy perspective. The choice of public policy has promoted innovative breakthroughs in artificial intelligen-ce. This article attempts to analyze the current situation of

the domestic artificial intelligence industry from the perspective of country comparison between China and the United States. On this basis, drawing on the relevant policies of the development of the artificial intelligence industry in the United States, the future development and reform of China's artificial intelligence industry is discussed from a policy perspective.

\section{COMPARISON OF THE DEVELOPMENT STATUS OF ARTIFICIAL INTELLIGENCE INDUSTRY IN CHINA AND THE UNITED STATES}

Looking at the development of artificial intelligence from an international perspective, China has entered a leading international group. The number of artificial intelligence companies, the scale of investment and financing, and the output of patent achievements are among the highest in the world, forming a "two-man" situation with the development of the United States. Although the development of China's artificial intelligence industry has achieved impressive results in recent years, from the perspective of development quality, China's artificial intelligence development is still far from being very optimistic, and there is still a large gap with the United States.

The United States has formed a comprehensive and balanced layout at the basic level, technical level, and application level. In terms of the number of enterprises, there are 1078 artificial intelligence enterprises in the United States, and the number of basic-level, technicallevel and application-level companies is 33, 586 and 488 (the same company may have multiple industrial levels), the ratio is about 1: $17.7: 14.7$; In China, the number of enterprises at all levels is 14,273 , and 304 respectively, with a ratio of about 1: 19.5: 23.4. In terms of talents, the number of professional talents at three levels in the United States is $17,900,29,400$ and 31,400 respectively, the ratio is about 1: 1.6: 1.7; in China, the number is $1,300,12,000$ and 24,300, the ratio is about 1: 9.2: 18.7. In terms of investment and financing scale, the key and hot areas (chips and processors, natural language processing and computer vision and imaging, intelligent driving) of China and the United States were selected for analysis at the three levels of basic layer, technical layer and application layer. The investment amounts were 30.818 billion, 29.297 billion, and 10.715 billion, respectively, with a ratio of about 1: 0.9: 0.3; China had 1.338 billion, 19.556 billion, and 7.220 billion, respectively, with a ratio of about 1 : 14.6: 5.4. It can be seen that compared with the United States, the development of China's AI industry shows obvious uneven characteristics. The ratio of the three levels of the basic layer, technical layer and application layer shows the same in the three indicators of enterprise layout, number of talents and financing scale. Characteristics: As the core and strong driving force of the artificial intelligence industry, it is not as good as the technology layer in terms of enterprise layout, number of talents, and financing scale, and it is significantly different from the application layer. The characteristics of industry layout are not conducive to the key technological breakthroughs and long-term development of the artificial intelligence industry.

Table 1 Comparison of the AI industry between China and the United States

\begin{tabular}{|c|c|c|c|c|c|c|}
\hline \multirow{2}{*}{$\begin{array}{c}\text { Industraial } \\
\text { Level }\end{array}$} & \multicolumn{3}{|c|}{ United States } & \multicolumn{3}{c|}{ China } \\
\cline { 2 - 7 } & Enterprise & $\begin{array}{c}\text { Qualified } \\
\text { personnel }\end{array}$ & $\begin{array}{c}\text { Financing } \\
\text { amount } \\
\text { (million yuan) }\end{array}$ & Enterprise & $\begin{array}{c}\text { Qualified } \\
\text { personnel }\end{array}$ & $\begin{array}{c}\text { Financing } \\
\text { amount } \\
\text { (million yuan) }\end{array}$ \\
\hline Basic level & 33 & 17900 & 308.18 & 14 & 1300 & 13.38 \\
\hline $\begin{array}{c}\text { Technical level } \\
\text { Application } \\
\text { level }\end{array}$ & 586 & 29400 & 292.97 & 273 & 12000 & 195.56 \\
\hline
\end{tabular}




\section{THE OPTIMIZED PATH OF THE DEVELOPMENT OF CHINA'S ARTIFICIAL INTELLIGENCE INDUSTRY}

\subsection{Sorting out American artificial intelligence policies}

From October to December 2016, the US government issued three consecutive policy documents on the development of artificial intelligence: "National Artificial Intelligence Development and Research Strategic Plan", "Preparing for the Future of Artificial Intelligence", "Artificial Intelligence, Automation" "Economics", make overall arrangements for the development of artificial intelligence from the national level. "National Artificial Intelligence Development and Research Strategic Plan" focuses on the purpose, vision, and key directions of the US artificial intelligence development strategy from a technical perspective; "Preparing for the Future of Artificial Intelligence" is mainly to discuss the government's promotion of technology from a governance perspective The role played by innovation; "Artificial Intelligence, Automation and Economy" is a supplement to "Preparing for the Future of Artificial Intelligence" from the perspective of labor market and economic development [4].

"National Artificial Intelligence Development and Research Strategic Plan" is the world's first national-level artificial intelligence development strategic plan. It has formulated the development route and strategy of artificial intelligence in the United States and proposed seven strategies for the development of artificial intelligence: basic research strategy, human-machine Interaction strategy, sociology strategy, security strategy, data and environment strategy, standard strategy and human strategy [5]. As the first of the seven strategies, the basic research strategy emphasizes long-term investment in artificial intelligence research; the human-computer interaction strategy proposes to develop effective human and artificial intelligence collaboration methods; the data and environmental strategy focuses on the development of artificial intelligence training and testing Public data sets and environments support the development and breakthrough of artificial intelligence technology with data; the standard strategy emphasizes the formulation of benchmarks and standards to measure and evaluate artificial intelligence technology, and regulates the development of artificial intelligence; the human strategy is to provide guarantee for the research and development of artificial intelligence. The National Artificial Intelligence Development and Research Strategic Plan promotes breakthroughs in artificial intelligence technology in terms of investment, data, standards, and manpower, which is enough to show the importance that the United States attaches to the basic support research of artificial intelligence.
"Preparing for the Future of Artificial Intelligence" elaborates on the potential of artificial intelligence technology and shows the expectations of the US government for the development of artificial intelligence technology [6]. The report mainly discusses the role and role of the government in artificial intelligence technology from the perspective of the government. The report pointed out that "the most important thing for the government at this stage is not supervision, but guidance and support." In the development of artificial intelligence, the government can assume multiple roles. In promoting technological development, emphasizing data openness and standardization construction, "Federal agencies should give priority to opening training data sets and artificial intelligence data standards." Algorithms and data are the two cornerstones of the development of artificial intelligence technology. The opening of data is conducive to the improvement and expansion of algorithm rules, the innovation of algorithm framework, and the breakthrough and application of artificial intelligence technology. In terms of talent training, "The National Science and Technology Commission 's Machine Learning and Artificial Intelligence Sub-Committee should cooperate with relevant departments to develop a research on the delivery of talents including artificial intelligence researchers, experts, and users to ensure the talents in the field of artificial intelligence. The scale, quality and diversity will increase appropriately. " In terms of industrial investment, on the one hand, it provides detailed regulations on government purchases of services and fiscal expenditures. The federal government provides grants to the state government to support its use of artificial intelligence related systems. At the same time, the terms of the grants must be reviewed. The results of the purchase of artificial intelligence-based products or services are transparent "; on the other hand, it emphasizes that various forces should be used, proposing" the industry should cooperate with the government "and" encourage private institutions to test whether and how they can bear the burden. Responsibly use artificial intelligence and machine learning technology to benefit society "and build a diversified development pattern of artificial intelligence development.

"Artificial Intelligence, Automation, and Economy", as a follow-up and supplement to "Preparing for the Future of Artificial Intelligence," proposes strategies for responding to the impact of artificial intelligence-driven automation on the entire US economy, emphasizing the release of the vitality of enterprises and workers and ensuring that American leadership in the field of artificial intelligence [7].

\subsection{The optimization path of China's artificial intelligence industry}

At present, China is gradually deploying the development of artificial intelligence from the national level. The "New Generation Artificial Intelligence Development Plan" is a 
national-level strategic plan specifically formulated for the development of artificial intelligence. It has made detailed plans for the future development goals and routes of artificial intelligence in China. However, compared with the high efficiency of the implementation of the US government's artificial intelligence policy, there is a significant lag in the implementation of China's policy. At present, it is mainly implemented by means of administrative instructions. The policy is not effective and the policy content is not comprehensive and detailed. In the choice of policy tools, environmental policies are used the most, and the government pays more attention to the formulation of macro-planning policies; the demandoriented policy tools are under-focused, lack of cooperation between the government and social capital, and the government has insufficient incentives for the development of the artificial intelligence industry As a result, the development of artificial intelligence lacks the proper "thrust" and "pull" [8]. In the future, the development of China's artificial intelligence industry should use the "New Generation Artificial Intelligence Development Plan" as a guiding document, adopt a mixed political incentive or economic incentive method, based on the promotion of core tackling technologies, and increase financial support for research and development of key technical products. Deepen the integration of artificial intelligence and the real economy as the goal, adhere to the "trinity" collaborative advancement of artificial intelligence research and development, product application, and industry cultivation, promulgate a number of specific industrial promotion policies, occupy the leading position in artificial intelligence development, and build an organic and collaborative industrial ecology [9].

\subsubsection{Accelerating the formulation of industrial incentive policies and strengthen the layout of basic research}

"Preparing for the Future of Artificial Intelligence" states that the federal government should give priority to the development of basic and long-term artificial intelligence research. As the core support of industrial development, artificial intelligence chips and algorithm frameworks are also important links that determine industrial development and industry dominance. Their strategic position and market value are far greater than the technical product layer and scene application layer. Under the increasingly severe international situation and increasing global competition pressure, to achieve independent R \& D and innovation, it is not enough to rely on enterprise investment alone. It requires the government to make reasonable arrangements to strengthen the artificial intelligence through a series of industrial incentive policies. Basic research layout.

At present, the development of the basic level of artificial intelligence in China mainly depends on the strength of scientific research institutions and enterprises. The toplevel planning and arrangements for basic technical research and related standards and standards at the national level are not enough, and the investment of funds is insufficient. As a typical technology and capital-intensive industry, the artificial intelligence industry needs more government assistance than traditional industries for its cultivation and development. In addition, most of the basic layers are artificial intelligence companies in the initial stage, and their technology research and development is even more Rely on government attention and stable investment. For these start-ups, the government should first increase long-term capital investment and increase government procurement of new products and services. The government 's first use can stimulate market demand for emerging products and services, and effectively expand the promotion and publicity of enterprises; when these When the development of the enterprise is relatively mature, the government should give the enterprise more space for independent development, and adopt transitional measures such as price subsidies to support the development of the enterprise [10]. Secondly, we must guide the power of the market and social capital, establish a special fund for the development of the artificial intelligence industry, focus on supporting the research and development of basic core technology, and increase research and exploration of basic technology development gaps, such as GPU and FPGA development. In addition, the government should clarify the main direction of the key areas of basic $\mathrm{R} \& \mathrm{D}$, continue to increase tax dividend support and subsidies for high-tech $R$ \& $D$ companies, and reward companies that have achieved major breakthroughs.

\subsubsection{Promoting the opening and sharing of data and establish an integrated platform for production, teaching and research}

In the United States, a large number of artificial intelligence startups are concentrated in traditional hightech enterprises such as Silicon Valley and New York, as well as famous universities and colleges, forming a perfect integrated system of production, education and research. Although China has many enterprises and scientific research institutions, it has not yet formed an organic and coordinated industrial ecosystem. Therefore, the government should take measures to promote the open sharing of data between scientific research institutions and enterprises, and accelerate the establishment of a technology innovation system that integrates production, teaching and research based on enterprises as the mainstay and scientific research institutes and universities as the main force.

Massive data is one of the basic advantages of the development of artificial intelligence in China. The government should seize the opportunity of big data construction, on the basis of building an artificial intelligence industry industry database, accelerate the construction of data opening and sharing platforms, and establish a sound data ecosystem [11]. On this basis, 
encourage artificial intelligence enterprises and scientific research institutes and universities to conduct extensive exchanges and cooperation based on data, overcome the disconnection between scientific research institutions located upstream of the industrial chain and enterprises located downstream of the industry, and strengthen artificial intelligence research and development Combining with production, vigorously promote the integration of industry, university and research institute innovation. In this process, whether it is a research institute, a university, or an artificial intelligence enterprise, it must be demand-oriented, accurately position the market and consumer needs, and form a long-term stable industry-university-research linkage model to promote the industrial chain. The close cooperation and matching degree of the downstream, in order to exert joint efforts to transform technology research and development and scientific research results, further create products and technologies that are easy to be applied on a large scale, and form an industrial cluster with international influence and competitive advantage.

\subsubsection{Building a diversified main body structure and cultivate intermediary organizations with industry influence}

The United States clearly stated in the national strategic plan of "Preparing for the Future of Artificial Intelligence" that the cooperation between the government and industry should be strengthened; it was again proposed at the "American Artificial Intelligence Summit" held in May 2018: The government coordinates and integrates industry and academia to maintain the leading position of the United States in the era of artificial intelligence. This shows the importance of building a diversified pattern of artificial intelligence development and promoting the development of artificial intelligence through publicprivate cooperation.

In the process of artificial intelligence technology research and development and product application, the government, as the main body of social governance, should play a guiding role in the entire industry, organize the lead to increase the integration of resources scattered in various enterprises and scientific research institutions, and promote enterprises and enterprises The connection of resources between scientific research institutions and scientific research institutions, and between enterprises and scientific research institutions promotes the free flow of various production factors, thereby forming an organic and interactive industrial ecology, creating products for specific scenarios, and achieving diversified production. At the same time, it also needs to be combined with various types of social capital, introduce social capital through a variety of financing channels, and promote the technological innovation and product application of artificial intelligence; accelerate the integration of artificial intelligence enterprises and traditional enterprises, making artificial intelligence technology an industrial transformation and upgrading The driving force encourages traditional enterprises to provide financial support for artificial intelligence research and development in a variety of ways, to create industrial parks with typical characteristics and achieve differentiated development. In addition, the government should pay attention to the service and guidance role of third-party institutions in the development of the artificial intelligence industry, and take measures to encourage leading companies in the industry to establish non-profit intermediary organizations such as industry appealing and influential associations, industry alliances, etc. Responsibilities for access qualifications, standardization construction, and enterprise supervision, forming a benign competition and interaction model for technological innovation.

\subsubsection{Improving talent training system and strengthen talent support}

The United States has formed a comprehensive and systematic talent training system. When building a talent team, it pays attention to the cultivation of basic-level professional talents, and research-oriented talents have outstanding advantages. China must balance the proportion of talents in the artificial intelligence industry, pay special attention to the number of talents at the basic level, and establish a two-pronged talent plan for talent introduction and cultivation.

On the one hand, in view of the current shortage of talent in the artificial intelligence industry, we must fully mobilize resources to cultivate a group of local professionals engaged in basic frontier research or through a series of talent introduction strategies and plans to encourage scientific research institutions and enterprises to adopt projects Cooperation, exchange visits, technical consultation and other means to introduce relevant technical talents from abroad, the government provides subsidies for the introduction of corresponding talents through financial policies. On the other hand, in the long run, it is necessary to establish a perfect personnel training system to provide human resources guarantee for the development of China's artificial intelligence industry. To this end, we must pay attention to the cultivation of professional talents in colleges and universities. Accelerate the construction of national key laboratories, research institutes and other scientific research platforms related to artificial intelligence majors in colleges and universities according to the national deployment, and pay attention to the investment of laboratory and research institute infrastructure; promote cooperation and exchanges between universities and enterprises across regions and provinces To give full play to the technical advantages of universities and the leading role of radiation from top universities; promote the construction of artificial intelligence disciplines in universities, build artificial intelligence curriculum systems, sort out the relationship between artificial intelligence majors and related disciplines such as mathematics, physics, computer and 
biology, and promote multi-disciplines Cross-integration, attach importance to the teaching of basic theories of artificial intelligence, and cultivate compre-hensive talents with comprehensive development.

\section{CONCLUSION}

Under the dual promotion of technological development and policy guidance, artificial intelligence is increasingly becoming a strategic technology that leads the future of the world. The strong social spillover benefits of artificial intelligence itself will penetrate into other fields and trigger social change. Therefore, the government's formulation of artificial intelligence industrial policies must always be predictable and proactive. This paper explores the difficulties faced by the development of China's artificial intelligence industry through the comparison of the development status of the artificial intelligence industry in China and the United States, and from the perspective of policy, on the basis of drawing on the experience of relevant US policies, it proposes to speed up the formulation of industrial incentive policies for China's reality,strengthen the layout of basic research; promote the opening and sharing of data, establish an integrated platform for production, education and research; build a multi-disciplinary structure and cultivate intermediary organizations with industry influence; improve the talent training system and strengthen the four policy recommendations for talent support in order to promote the healthy development of China's artificial intelligence industry.

\section{ACKNOWLEDGMENT}

This work was supported by a major project of the new think tank in Sichuan Province: Promoting Research on the Development of Sichuan Artificial Intelligence Industry (H04W190619).

\section{REFERENCES}

[1] The State Council's notice on the issuance of the "New Generation Artificial Intelligence Development Plan."[A/OL]. [2018-5-31].

[2] Zhang Su, Xu Hui, Huang Rui. Research on the development of artificial intelligence industry in China [J]. Journal of Changchun University of Science and Technology (Social Science Edition), 2018, 31 (05): 16.

[3] Jia Kai, Jiang Yuhao. Three basic issues of artificial intelligence governance: technical logic, risk challenges and public policy choices [J]. China Administration, 2017 (10): 40-45.

[4] Jia Kai, Guo Yuhui, Lei Hongzhu. International Comparative Research on Artificial Intelligence Public Policy: History, Features and Enlightenment [J]. Egovernment, 2018 (09): 78-86.

[5] White House of the United States. "Preparing for the Future of the Artificial Intelligence" report (Preparing for the Future of the Artificial Intelligence) EB / OL]. White House official website, [2016--10-12].

[6] The National Science Council. The National Artificial Intelligence Research and Development Strategic Plan [EB / OL]. White House official website, [2016-10-13].

[7] Presidential Administration Office. "Artificial Intelligence Automation, and the Economy" report [EB / OL]. White House official website, [2016-12-20].

[8] Liu Hongbo, Lin Bin. Value orientation, issue construction and path selection of the development of artificial intelligence in China-Quantitative research based on policy texts [J]. E-government, 2018 (11): 4758.

[9] CCID think tank artificial intelligence industry situation analysis team. 2019 China artificial intelligence industry development situation outlook [N]. China Computer News, 2019-01-28 (008).

[10] Zhang Su, Xu Hui, Huang Rui. Research on the development of artificial intelligence industry in China [J]. Journal of Changchun University of Science and Technology (Social Science Edition), 2018, 31 (05): 16.

[11] Yu Hanchao, Liu Huihui, Wei Xiu, Yu Jiang. Analysis and suggestion of artificial intelligence policy [J]. Science and Technology Herald, 2018, 36 (17): 75 82. 